\section{Ensino de Língua de Sinais Brasileira como primeira língua: currículo em práticas no estágio do Letras Libras}

Teaching Brazilian Sign Language as first language: curriculum in practices of supervised stage of Letras Libras' Course

Margarida Maria PIMENTEL-SOUZA (UFC) mmps@delles.ufc.br

Sandra Patrícia de FARIA-NASCIMENTO (UnB) sandra.nascimento@unb.br

Francisca Geny LUSTOSA (UFC) franciscageny@yahoo.com.br

Recebido em: 15 de jun. de 2018. Aceito em: 15 de set. de 2018.

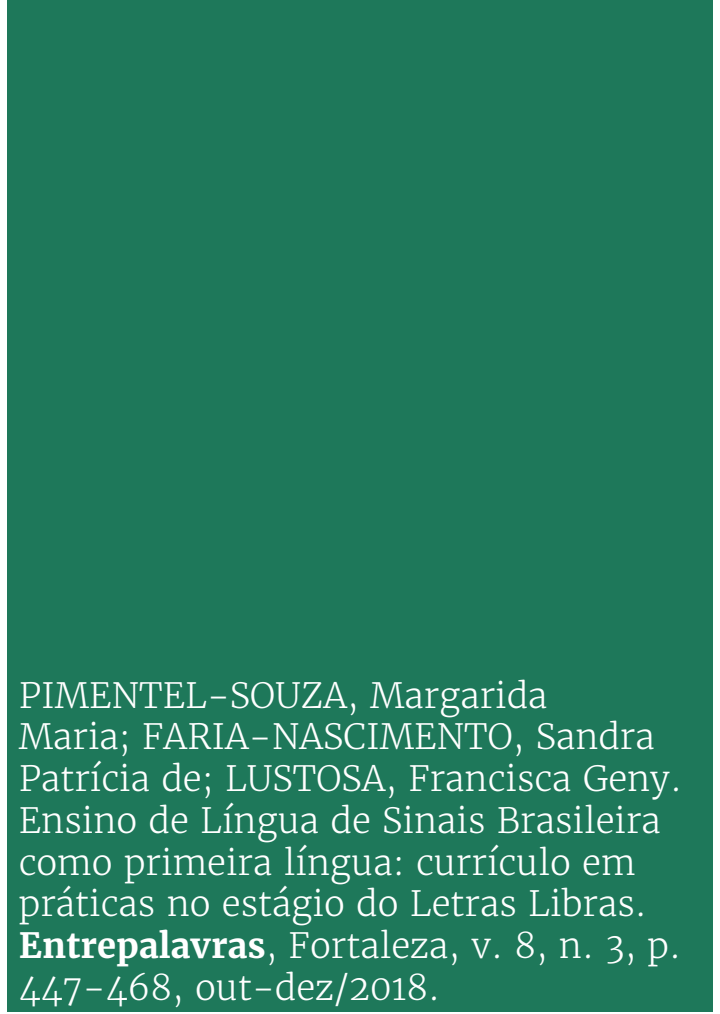

Resumo: Este artigo partilha experiências do estágio supervisionado do Curso de Licenciatura em Letras-Libras, no ensino da Língua de Sinais Brasileira (Libras ou LSB) como primeira língua (L1), sob três aspectos interrelacionados: (a) o estágio como vivência reflexiva e colaborativa; (b) a imersão do estudante em prática docente sociointeracionista, refletindo sobre os conceitos de língua materna e o currículo de Libras como L1; e (c) a escola como território de produção de cultura, lugar de (des)territorialização dos estágios e (des)construção de identidades dos estudantes. Os dados para análise foram extraídos dos registros do estágio da primeira turma de Letras Libras/UFC, em atividades produzidas nos semestres letivos 2017.1 e 2017.2. Os fundamentos teóricos que embasaram as experiências desse estágio foram desenvolvidas por meio da Sequência (Didática) Fedathi (BORGES-NETO, 2017a; 2017b), apoiaram-senoaporte sociointeracionista proposto por Vygotsky (1989; 1993), no ideário da consciência metalinguística (GIUSTINA; ROSSI, 2008), em intercessão com literatura específica na área da surdez (LANE, 1992; SACKS, 1998). Os relatórios apresentados pelos estagiários, em Libras, refletiram os resultados da 
v. 8 (3)

447-468 out-dez 2018

empiria, apresentando a urgência da sistematização do currículo de Libras como L1, nos diferentes níveis de ensino. Ao final desta experiência, pode-se afirmar que as diferentes etapas problematizaram o currículo, a escola e o ensino de Libras como L1, e oportunizaram vivências da tríade: educando (da escola), estagiário e professores (supervisores), delineando um arcabouço rizomático, como ponte à constituição da profissionalização dos (futuros) docentes de Libras.

Palavras-chave: Estágio. Ensino de Libras. Primeira Língua (L1). Currículo.

Abstract: This article shares experiences of the supervised traineeship of the Licentiate Course in Letras Libras, in the teaching of the Brazilian Sign Language (Libras or LSB) as first language (L1), under three interrelated aspects: (a) the traineeship as a reflexive and collaborative experience; (b) the student immersion in socio-interactive teaching practice, reflecting on concepts of mother tongue and curriculum of Libras as L1; and (c) the school as territory of culture production, place of (de)territorialization of stages and (de)construction of students' identities. The data for analysis were extracted from records of the traineeship of the first class of Letras Libras/UFC, in activities produced in the following academic semesters: 2017.1 and 2017.2. The theoretical foundations that supported the experiences of this traineeship were developed with Fedathi Sequence (BORGES-NETO, 2017a, 2017b) which is based on socio-interactive contribution proposed by Vygotsky $(1989,1993)$ under the ideology on metalinguistic consciousness (GIUSTINA; ROSSI, 2008) and the intercession with specific literature on deafness (LANE, 1992; SACKS, 1998). The reports presented by the students, in Libras, reflected the results of the empiria, presenting the urgency to systematize Libras' curriculum as L1 in different levels. At the end of this experience we can affirm that the different stages problematized curriculum, school and teaching of Libras as L1; and it gave us opportunities for the triad experiences: student (from school), trainee and teachers (supervisors), outlining a rhizomatic framework as a bridge to the constitution of the professionalization of the (future) Libras' teachers.

Keywords: Traineeship. Teaching Libras. First language (L1). Curriculum.

\section{Introdução}

A língua de sinais é para os surdos "a chave que abre a grande porta", como narra Emmanuelle Laborit (1994, p. 69) em seu livro "O voo da Gaivota". A língua de sinais permite o compartilhar de ideias, pensamentos, emoções, conhecimentos, por serem os surdos "seres humanos comunicadores" (LABORIT, Ibid, p. 09), como qualquer pessoa (ouvinte-falante). A autora, em sua autobiografia, ratifica a língua que promoveu significativas descobertas em seu mundo; língua fundamental aos seus pares surdos; com a qual os surdos naturalmente se expressam, pois, como diz a autora, ao mencionar como adquiriu sua língua(gem), "aquilo saía, saía, como uma grande abertura em direção à luz." (LABORIT, Ibid, p. 75).

\footnotetext{
${ }^{1}$ Esse livro, originalmente intitulado "Le cri de la mouette", pode ser encontrado na versão de Portugal: LABORIT, Emmanuelle. O grito da gaivota. Lisboa: Ed. Caminho, 2000. Vale destacar que, em canais de busca da internet, um livro de enfoque diverso à história de Emmanuelle Laborit pode ser encontrado com o mesmo título na versão brasileira, "O voo da gaivota", mas com outra autora e temática diversa.
} 
A língua de sinais natural, de Laborit, é a Língua de Sinais Francesa - LSF. Entretanto, suas narrativas são semelhantes às dos surdos de todas as partes do mundo, visto que sempre que duas pessoas surdas $^{2}$ (ou mais) se encontram, certamente, se expressam em sinais (ou gestos), conforme lembra Sacks (1998) ao citar J. Schuyler Long (1910), na epígrafe de sua obra intitulada "Vendo vozes". Esse falar em sinais/gestos, que aproxima surdos de diferentes nacionalidades e culturas, é promovido por universais linguísticos ${ }^{3}$ e é uma modalidade que favorece o acolhimento, a interação entre línguas de sinais, seus dialetos e suas diferenças linguísticas das mais variadas regiões de um país e do mundo.

Nesse contexto, delineamos questões pertinentes às peculiaridades da Língua de Sinais Brasileira como primeira língua (L1) e suas implicações nas práticas de estágio obrigatório no Curso de Letras Libras, em especial no cenário fortalezense. Este texto passeia pelas experiências em escolas específicas e nas salas de aula da Universidade, sob os fundamentos de estudos sobre mediações (VIGOSTSKY, 1989; 1993) e consciência metalinguística (GIUSTINA; ROSSI, 2008); Educação de Surdos (LANE, 1992; SACKS, 1998; PIMENTEL-SOUZA, 2008); Políticas e Legislação específica da área; e Currículo de Libras (BASSO; STROBEL; MASUTTI, 2009). Do ponto de vista metodológico, o estágio desenvolveu-se com sessões didáticas à luz de uma metodologia de ensino denominada Sequência Fedathi (BORGES-NETO, 2017a; 2017b), visando promover vivências reflexivas e colaborativas em torno do conceito de Libras como L1, suas práticas e seu(s) currículo(s).

Na intenção de lançar "fagulhas" e suscitar debates, este texto divide-se em seções, como a construir pontes de/para reflexões. A primeira seção refere-se às considerações gerais e históricas sobre a Libras como primeira língua (L1), o que implica um diferente olhar quando se trata dos sujeitos em processo de aquisição, ensino e aprendizagem. A segunda seção compila aspectos relacionados ao Estágio Curricular Supervisionado (ECS), obrigatório nos cursos de Licenciatura, além de alguns desafios no âmbito do Letras Libras em Fortaleza. A terceira

\footnotetext{
${ }^{2}$ Especialmente, as pessoas com surdez congênita profunda.

3 Um mito amplamente difundido é o de que a língua de sinais é universal. Entretanto, basta lembrar que uma língua, quer seja oral ou escrita, como produto de uma cultura, possui suas diferenças linguísticas, falares e nuances próprias de cada lugar. Assim, cada país possui sua língua de sinais, mesmo apresentando similitudes, como aquelas que pertencem a um mesmo tronco linguístico, tais como a LSF, a ASL e a LSB; e entre as línguas orais, o português, o espanhol, o francês entre outras.
} 
v. 8 (3)

$447-468$ out-dez 2018

traz as experiências e narrativas relacionadas ao Estágio à luz da abordagem sociointeracionista e no desenvolvimento de uma práxis (meta)linguística. A quarta seção sintetiza o percurso metodológico, e a quinta apresenta os resultados da proposta de ECS na perspectiva em que se desenvolveu, dividida em etapas de uma sequência didática, a fim de gerar uma ação reflexiva e colaborativa.

\section{Aspectos (do passado e do presente) convergentes nas experiências de ensino de Libras como primeira língua}

As primeiras referências à maneira de expressão dos surdos remontam, aproximadamente, ao ano 368 a.C.4 , quando o filósofo grego Sócrates comenta no Crátilo de Platão: "Se não tivéssemos voz nem língua e ainda assim quiséssemos expressar coisas uns aos outros, não deveríamos, como aqueles que ora são mudos, esforçar-nos para transmitir o que desejássemos dizer com as mãos, a cabeça e outras partes do corpo?" (PIMENTEL-SOUZA, 2008, p. 67).

Mais adiante, sobre o modo de interagir dos surdos, Vygotsky, nos Fundamentos da Defectologia (1989), traz registros quanto à importância do uso da "mímica" 5 na educação de surdos. De acordo com os dados históricos, no entanto, o reconhecimento do status linguístico da(s) Língua(s) de Sinais só ocorreu na década de 1960, quando William Stokoe publicou a primeira descrição estrutural da Língua de Sinais Americana - ASL, na qual faz analogia desta com as línguas orais e propõe uma análise das unidades sinalizadas em unidades mínimas (queremas/quiremas) $^{6}$. (PIMENTEL-SOUZA, 2008, p. 68)

Quanto ao uso de sinais na educação de crianças surdas, a historiografia nos conta que o abade francês Charles Michel de L'Epée (1712-1789), reconhecido como criador do Gestualismo, na intenção de educar indivíduos economicamente desfavorecidos, ensinando-lhes a língua francesa falada e escrita, criou os "Sinais Metódicos", agregando à linguagem de sinais7 dos surdos parisienses outros sinais inventados em sua interação com seus educandos (SACKS, 1998; LEITÃO, 2003;

\footnotetext{
${ }_{4}$ Cf. Felipe e Monteiro (2004).

${ }^{5} \mathrm{~A}(\mathrm{~s})$ língua(s) de sinais, no período dos estudos de Vygotsky, ainda não tinha(m) comprovado o seu status linguístico, por isso o uso da expressão "mímica".

6 Termo derivado do grego, lembrando "mão", usado em substituição ao termo "fonema", na intenção de evitar subestima à língua de sinais.

7 No período destacado, como à época de Vygotsky, a LS não possuía status linguístico e era tida como um tipo de linguagem ou sistema de gestos.
} 
PIMENTEL-SOUZA, 2008). Nesses registros, constatamos que L'Epée, mesmo na intenção de ensinar o francês, não somente criou a primeira escola para surdos e o Gestualismo, mas também inaugurou os primeiros passos de ensino da língua(gem) de/para surdos. Anos mais tarde, os surdos formados pela escola - o Instituto de Surdos-Mudos de Paris passavam a compor o quadro de professores da própria instituição.

No Brasil, antes mesmo do reconhecimento da língua de sinais, como meio de interação de seus falantes, no ano de 2000, a Lei da Acessibilidade, n. ${ }^{0}$ 10.098, inclui em seu Artigo 17, as garantias de acesso dos surdos aos diversos espaços e informações a que todo cidadão tem direito. Dois anos mais tarde, enfim, a Libras foi oficializada em nível federal, por meio da Lei n. ${ }^{0} 10.436$, em 24 de abril de 2002, a qual foi regulamentada no Decreto n. ${ }^{0}$ 5.626, em 22 de dezembro de 2005. Esse Decreto traz uma série de implicações, entre as quais se encontra a obrigatoriedade da inclusão da disciplina de Libras no currículo dos cursos de formação de professores em níveis médio e superior, de instituições públicas e/ou particulares, e nos cursos de fonoaudiologia; além de orientações relacionadas à formação de professores, instrutores e tradutores e intérpretes de Libras; educação bilíngue, entre outros aspectos. Desse modo, não somente como modo de interação, mas como língua legítima, a Língua de Sinais Brasileira ficou reconhecida oficialmente como:

forma de comunicação e expressão, em que o sistema linguístico de natureza visual-motora, com estrutura gramatical própria, constitui um sistema linguístico de transmissão de ideias e fatos, oriundos de comunidades de pessoas surdas do Brasil. (Lei n. ${ }^{\circ}$ 10.436, Art. $1 .^{\circ}$, Parágrafo único)

Convém destacar que as línguas de sinais não são ágrafas, muito embora não haja ainda um sistema de escrita universal padronizado8 ${ }^{8}$ Nesse contexto, tem-se o sistema signwriting, já utilizado em diversos países e que se constitui uma forma de registro totalmente diferente do sistema alfabético, mas legítimo; sendo criado especificamente para retratar os caracteres próprios de uma língua visuoespacial.

Após a regulamentação da Lei de Libras pelo Decreto citado, o ensino da Libras, até então abordado mais numa perspectiva de

\footnotetext{
8 No Brasil, pode-se contar pelo menos quatro registros: o sistema Signwriting, criado por Valerie Sutton (San Diego/EUA), é o mais propagado pelo mundo e é o sistema que é adotado no curso de Letras Libras; o sistema ELiS, criado e aprofundado por Mariângela Estelita (UFGO); o SEL, desenvolvido por Adriana Lessa-de-Oliveira (UESB); além da Visografia, desenvolvido por Claudio Alves Benassi (UFMT).
} 
V. 8 (3)

447-468 out-dez 2018

ensino de segunda língua (L2) para ouvintes, em cursos oferecidos por entidades de surdos ${ }^{9}$, passou por novos olhares numa perspectiva de primeira língua (L1), a partir do curso de Letras Libras ofertado, em $2006^{10}$, com as disciplinas de metodologias de ensino e estágios.

Vários são os desafios no âmbito da educação de surdos. Entretanto, no âmbito do ensino de Libras como L1, a investidura de pesquisas e resultados de práticas didáticas ainda se apresenta incipiente, visto haver muitas questões relacionadas aos currículos dos cursos de Letras Libras e lacunas nas práticas e nos currículos da disciplina de Libras como língua materna, nas escolas. No ensino de Libras como L1, ainda há muitos passos a trilhar, da mesma forma que o ensino das línguas orais para seus falantes nativos ainda são fontes de investigação, pois "é de se supor que o conhecimento sobre língua aperfeiçoará o uso da língua pelas crianças" (STUBBS, 2002, p. 153).

Assim, esboçadas as reflexões do contexto exposto, segue-se a próxima seção com a apresentação de nuances específicas do Estágio Curricular Supervisionado em discussão.

\section{Os desafios preliminares do Estágio obrigatório de Libras como L1}

O Estágio Curricular Supervisionado (ECS) constitui uma atividade obrigatória, vinculada ao Projeto Pedagógico do Curso, integrando o itinerário formativo dos estudantes. De acordo com a Lei Federal n. ${ }^{0} 11.788 / 2008$, o Estágio é garantido como uma:

preparação para o trabalho produtivo de educandos que estejam frequentando o ensino regular em instituições de educação superior, de educação profissional, de ensino médio, da educação especial e dos anos finais do ensino fundamental, na modalidade profissional da educação de jovens e adultos.

Nesse contexto, a referida Lei busca garantir ao educando o aprendizado necessário ao cumprimento de atividade profissional ante a contextualização curricular, a fim de promover o seu desenvolvimento para a vida cidadã e para o trabalho.

\footnotetext{
9 Associações de Surdos; Federação Nacional de Educação e Integração de Surdos (Feneis), entre outras.

10 Curso desenvolvido pela Universidade Federal de Santa Catarina (UFSC), oferecido, inicialmente, para nove instituições federais (polos): Universidade Federal de Santa Catarina (UFSC), Universidade Federal do Ceará (UFC), Universidade Federal da Bahia (UFBA), Universidade Federal do Amazonas (UFAM), Centro Federal de Formação Tecnológica de Goiás (CEFET - GO), Universidade de Brasília (UnB), Universidade de São Paulo (USP), Universidade Federal de Santa Maria (UFSM) e Instituto Nacional de Educação de Surdos (INES).
} 
No âmbito da Universidade Federal do Ceará (UFC), essa complementação curricular do ensino e da aprendizagem é realizada pelos estudantes matriculados e efetivos junto a pessoas jurídicas de direito privado, organizações não-governamentais (ONGs), órgãos da administração pública e instituições de ensino (UFC, 2016a).

As experiências de ECS relatadas nesse estudo ocorreram em duas escolas específicas para educandos surdos ${ }^{11}$, o Instituto Cearense de Educação de Surdos (ICES) e o Instituto Filippo Smaldone (IFS), por se tratar do ensino de Língua de Sinais Brasileira (Libras) como primeira língua (L1). Sem abordar por ora a questão curricular, eis um dos primeiros desafios: o campo restrito de estágio, visto que Fortaleza possui (apenas) duas escolas com a disciplina Libras na grade curricular. As escolas de inclusão com surdos matriculados não possuem a disciplina Libras como componente curricular. Assim, as poucas salas a serem distribuídas pelos estagiários tornaram-se menos ainda, pois, no período do estágio, 2017.1 e 2017.2, tais escolas também acolhiam estagiários do Curso de Instrutores de Libras de uma escola profissionalizante do sistema estadual de ensino. Esse grupo de estagiários já ocupava a maioria das salas.

Nesse sentido, em face da necessidade de ampliação do campo de estágio para acolher os formandos em Letras Libras e atender, não somente à LDB, que já definia os profissionais a atuarem na Formação Básica, mas também ao Decreto n. ${ }^{0}$ 5.626/2005, cabe às escolas a verificação desses documentos, como o Decreto que esclarece:

Art. $4^{\circ}$ A formação de docentes para o ensino de Libras nas séries finais do ensino fundamental, no ensino médio e na educação superior deve ser realizada em nível superior, em curso de graduação de licenciatura plena em Letras: Libras ou em Letras: Libras/Língua Portuguesa como segunda língua.

Ainda tratando sobre os campos de atuação de profissionais, o Decreto n. ${ }^{0}$ 5.626/2005 também aponta aspectos relacionados à educação infantil e aos anos iniciais do ensino fundamental, a partir de sua formação, conforme esclarece o Art. $5 .^{\circ}$ desse Decreto:

A formação de docentes para o ensino de Libras na educação infantil e nos anos iniciais do ensino fundamental deve ser realizada em curso de Pedagogia ou curso normal superior, em que Libras e Língua Portuguesa escrita tenham constituído línguas de instrução, viabilizando a formação bilíngue.

${ }^{11}$ Escolas com proposta de educação bilíngue, registradas no Sistema Educacional como Escolas Especiais. 
V. 8 (3)

447-468 out-dez 2018

Nesse contexto, surge uma questão: as escolas e entidades estão cientes do campo de atuação do Instrutor de Libras e, portanto, de seu campo de estágio?

O Decreto veio regulamentar variados aspectos relacionados à Libras, como a questão do ensino a ser ministrado, seja por Professor de Libras, seja por Instrutor de Libras, estes últimos inicialmente formados por entidades, como a Federação Nacional de Educação e Integração de Surdos (Feneis) ou como Associações de Surdos. Sobre a Formação destes, reza o Art. $6^{\circ}$ que:

\footnotetext{
A formação de instrutor de Libras, em nível médio, deve ser realizada por meio de:

I - cursos de educação profissional;

II - cursos de formação continuada promovidos por instituições de ensino superior; e

III - cursos de formação continuada promovidos por instituições credenciadas por secretarias de educação.
}

A LDB n. ${ }^{0}$ 9.394/1996, entre diversas considerações, aponta quais são os campos de estágio e atuação do Pedagogo e de Profissionais de Letras. O Decreto n. ${ }^{0}$ 5.626/2005 evidencia, por sua vez, os campos específicos de atuação do Pedagogo Bilíngue (formado nos cursos de graduação em Pedagogia Bilíngue), do Professor de Libras (graduado em Letras Libras), assim como do Instrutor de Libras, seja para o ensino de tal língua como L1 seja como L2. Desse modo, parece claro que as salas de aula das escolas de Educação Básica constituem-se campo de estágio, prioritariamente, dos cursos de Pedagogia (bilíngue ou não) e Letras Libras, resguardados os devidos níveis de ensino.

Os aspectos suprarrelacionados fazem alusão aos espaços de atuação de um grupo de profissionais ou aprendizes, um panorama comum em várias regiões do país. Tal panorama pode apresentar situações mais desafiadoras nos locais em que não há escolas específicas/bilíngues, onde os educandos surdos não estão partilhando o mesmo espaço com seus pares. Nesse sentido, em consonância com o modo visual de SER SURDO, o ECS do Ensino de Libras como L1 do Curso de Letras Libras da UFC segue a legislação nacional, bem como as normas internas das instituições concedentes (as escolas) e a Resolução CEPE n. ${ }^{0}$ 32/2009 (UFC, 2009), além das orientações da Agência de Estágio/UFC e de manuais próprios.

Para dar continuidade à discussão iniciada, segue uma seção que descreve as vivências realizadas durante as atividades de ECS, suscitando reflexões que buscam promover discussões com vistas a dirimir "fios frouxos" na trama do ensino de Libras como L1, mas que evidenciam nuances e colorido que o produto criativo pode despontar. 


\section{Língua(gem) e mediação nas experiências de ECS: alguns passos sociointeracionistas no processo de consciência (meta)linguística}

O comportamento do ser humano diante daquilo que o rodeia é resultado de mecanismos biológicos elementares e de atividades mentais complexas, consideradas superiores. Estas últimas, segundo os postulados vygotskyanos, exigem comportamento deliberado, tipicamente humano, como o fato de praticar solidariedade, ficar atento enquanto o outro fala, entre outros.

Nessa perspectiva, as relações do homem com o mundo não se dão de forma direta e, sim, essencialmente mediada. Segundo Vygotsky (1993), as relações se dão por dois elementos mediadores: os instrumentos e os signos. Os primeiros são, por exemplo, os instrumentos propriamente ditos, que levam a ações como ler livros, aparar gramas com um cortador ou arrumar as unhas com uma lixa. Os segundos ocorrem num plano simbólico, podendo estar ou não sendo representados por algum "símbolo" concreto, como o uso das placas ilustrativas ou uma explicação de alguém, ou ainda, pode ocorrer diretamente em caráter interior. Assim, a linguagem é o ponto-chave dessa mediação.

O respaldo sociointeracionista no âmbito de escolares surdos encontra uma considerável relevância, ao atentarmos para o fato de que, sem a LS, tais sujeitos ${ }^{12}$, no geral, expressam seus pensamentos estreitamente relacionados à presença de instrumentos, um tipo de pensamento por complexos na teoria vygotskyana. Assim, vale ressaltar que, numa sala de aula com discentes surdos, independente da equivalência de suas idades, evidencia-se um distanciamento no grau de proficiência. Isto significa que, no caso do processo de ensino e aprendizagem de/para surdos, importa saber o período de contato de tais sujeitos com a LS, que adquirem espontaneamente, mas com que nem sempre o contato se dá desde a mais tenra idade.

Nesse sentido, o estudo da formação de conceitos é primordial. Em tal processo, a primeira fase é constituída pelo pensamento sincrético, no qual os critérios de formação são mutantes e, naturalmente, não relacionados com as palavras que poderiam orientar a classificação.

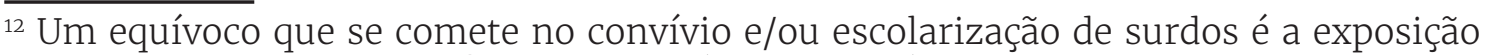
destes a apenas o Português, por ser a língua do país e, principalmente, pelo fato de pertencerem, em geral, a famílias de ouvintes. De acordo com pesquisas (LANE, 1992; SACKS, 1998), 90\% a 95\% das crianças surdas têm pais ouvintes. E apenas os 5\% das crianças surdas filhas de surdos se desenvolvem de modo equivalente às crianças ouvintes em virtude do ambiente linguístico favorável.
} 
v. 8 (3)

447-468 out-dez 2018

Na fase seguinte, a do pensamento por complexo, o sujeito baseiase em vínculos reais manifestados através da experiência imediata. O complexo assim é definido como o agrupamento de um conjunto de objetos concretos sobre a base da vinculação real entre eles. Nesse sentido, Pimentel-Souza (2008, p. 88) complementa, esclarecendo que:

as fases posteriores aos complexos são os pseudoconceitos e conceitos propriamente ditos. O primeiro trata-se do elo de ligação entre o pensamento concreto e o abstrato. Essa fase apresenta uma propriedade importante que são os "equivalentes funcionais", através dos quais a criança e o adulto se entendem, pois a primeira utiliza os conceitos comuns aos adultos mesmo não tendo consciência, visto que ainda não há um pensamento conceitual. O pensamento por conceitos propriamente ditos pressupõe além da união e da capacidade de generalização, a capacidade de abstrair e de considerar os elementos fora das conexões reais e concretas dadas. Para Vygotsky o que caracteriza o pensamento por complexo é a superabundância de conexões e ausência de abstração.

Nessa perspectiva, considerando que o percurso da consciência de conceitos segue e amadurece conforme as interações estabelecidas nos ambientes e com sujeitos mais experientes, o que promove a emergência da zona de desenvolvimento proximal, é papel dos professores estabelecer condições para a aquisição/desenvolvimento dos conceitos, bem como para distinção dos conceitos cotidianos e científicos. É nisto que se encontra, de acordo com Vygotsky, a especificidade da escola ${ }^{13}$. (FRIEDRICH, 2012, p. 99)

$\mathrm{O}$ aporte em Vygotsky, portanto, o olhar para as nuances e a complexidade da Libras, considerando os estudos sobre a consciência metalinguística (GIUSTINA; ROSSI, 2008), foi importante para se delinearem as atividades de construção de material pelos estudantesestagiários, adequando-as ao programa dos planos de curso das turmas das escolas, com a busca de um trabalho reflexivo e colaborativo. Nesse viés, as habilidades de metacognição foram emergindo, saltando aos olhos deles próprios. De acordo com Giustina e Rossi (2008, p. 32):

a consciência metalinguística pragmática consiste na reflexão dos aspectos da língua em uso, isto é, uma reflexão sobre o emprego dos recursos linguísticos. A produção escrita implica a utilização desse tipo de consciência para estruturar os elementos linguísticos (fonemas, grafemas, orações, parágrafos, etc.), organizar o pensamento, além de coordenar todos estes fatores com as exigências contextuais. Assim, a consciência metalinguística que é adquirida ao longo do processo de ensino, possibilita o desenvolvimento de outra habilidade metacognitiva, a consciência metalinguística pragmática, que auxilia o próprio sujeito no seu processo de aprender, de aprender a escrever.

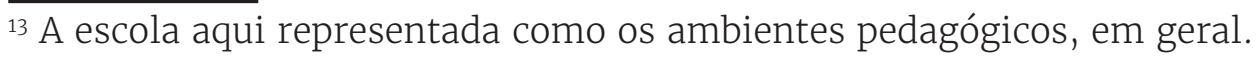


De um modo geral, mesmo as autoras focando as questões relacionadas à escrita, o desenvolvimento do ECS tomou as contribuições no âmbito da consciência metalinguística, adicionalmente, quando, nas reflexões sobre o uso da Libras nos diferentes contextos e gêneros textuais, notou-se a menor abrangência da escrita de sinais, dada a complexidade e pouco uso do sistema signwriting pelos estudantesestagiários e pelos discentes da escola (mesmo sendo parte do conteúdo do plano anual de suas turmas).

Assim, conhecido esse panorama, passamos à próxima seção que traz uma síntese contextual do percurso das experiências do Estágio.

\section{Percursos Metodológicos à luz da Sequência (Didática) Fedathi}

A construção teórico-metodológica dos trabalhos do ECS tomou o arcabouço sociointeracionista e o da consciência metalinguística, permeando uma abordagem metodológica desenvolvida por BorgesNeto (2017a; 2017b), denominada Sequência Fedathi ${ }^{14}$ (SF). Esta se desenvolve em quatro fases: a (1) tomada de posição, na qual se apresenta o "problema"; a (2) maturação, fase em que os estudantes são estimulados a reflexões, hipóteses e formulações; a (3) solução em que, sob a mediação do professor, os estudantes discutem suas formulações, possíveis erros e acertos, e buscam soluções para o problema apresentado que possam satisfazer em diferentes situações; e a (4) prova, que se constitui na fase final, em que o aprendiz apresenta um modelo geral, um conhecimento novo, fruto do seu trabalho reflexivo e interativo com seus colegas e com o professor.

Nessa perspectiva, considerou-se ainda os pressupostos de Franco $(2005,490)$, quando orienta que: (a) a práxis deve ser concebida como mediação básica na construção do conhecimento, que, por sua vez, não se restringe à mera descrição, pois busca a explicação; (b) não há como separar sujeito (conhecido) do objeto (a ser conhecido); a interpretação dos dados é realizada apenas em contexto; (c) o saber produzido é necessariamente transformador dos sujeitos e das circunstâncias.

\footnotetext{
${ }^{14}$ A Sequência Fedathi (SF) foi sistematizada por Borges-Neto, em 1996, por ocasião de seu Pós-Doutorado na Université Denis Dideot, Université de Paris VII. Nos últimos anos, pesquisadores de diferentes áreas (ARAÚJO-SOUZA, 2013; SOUSA, 2017; SOARES, 2017, entre outros) passaram a tomar a SF como abordagem metodológica em suas práticas, pesquisas e testagens, dentro e fora de sala de aula. De acordo com BorgesNeto (apud ARAÚJO SOUZA, 2013, p. 18), a Sequência Fedathi propõe que, ao deparar com um problema novo, o aluno deve reproduzir os passos que um matemático realiza quando se debruça sobre seus ensaios.
} 
v. 8 (3)

447-468 out-dez 2018

Em acréscimo, a escolha do caminho metodológico percorrido nessa experiência de ECS decorre da concepção adotada para o sujeito. No caso em foco, tratava-se de uma turma mista, sob a orientação de dois professores (um surdo e uma ouvinte), com nove estudantes surdos e treze ouvintes (não-surdos), apresentando diferentes graus de proficiência em Libras. É importante lembrar, conforme dito anteriormente, que muitos surdos, por pertencerem a lares de ouvintes, têm o seu contato com a LS tardiamente, o que representa a sedimentação de maiores barreiras e "prisão" (LABORIT, 1994, p. 52), principalmente aos que nascem com surdez profunda. Tal aspecto, em uma mesma sala, é percebido nas expressões e comportamentos dos sujeitos que refletem sua posição nas distintas etapas do processo de formação de conceitos, dos estudos vygotskyanos. Assim, alguns necessitam de diferentes instrumentos mediadores (inclusive materiais) associados ao signo linguístico, perspectivando a abstração.

Nesse sentido, após a elaboração do plano à luz da SF, em 2017.1, as atividades ${ }^{15}$ de ECS de Ensino de Libras como L1 - II foram iniciadas. A turma encontrava-se no $8 .^{\circ}$ semestre e para a qual foram feitas as seguintes indagações (aplicando a ETAPA 1 da SF): (1) "O que você entende de Libras como L1?"; (2) "No ensino de Libras como L1, qual o público-alvo?"; (3) "O que abordar?"; (4) "Estágio supervisionado por que e para quê?"; (5) "O que é para você essa fase de ECS?"

A resposta mais comum e repetida pelos discentes surdos foi: "LIBRAS L1 SURDOS, PORTUGUÊS L2. LIBRAS L2 OUVINTES"16. É possível inferir que, na ocasião, já tinham conhecimento da legislação. A resposta também reflete o parâmetro que tinham de que o ensino de Libras era apenas para ouvintes, com base nas experiências de ensino em que somente ouvintes faziam cursos de Libras (como L2). As respostas também demonstravam não somente as lacunas decorrentes da falta de um currículo sistematizado ${ }^{17}$ de Libras como L1, com suas

${ }_{15}$ Conforme o Projeto Pedagógico do Curso (UFC, 2016b), o ECS da primeira turma de Letras Libras se dividia em três etapas: (a) $7^{\circ}$ semestre: ECS Libras como L1 I (Observação); (b) $8^{\circ}$ semestre: ECS Libras como L1 II (Planejamento); e (c) $9^{\circ}$ semestre: ECS Libras como L1 III (Regência). Os dois professores da experiência em tela assumiram a partir da segunda etapa, do Planejamento à Regência (II e III), nos períodos letivos de 2017.1 e 2017.2, respectivamente, visto que os professores que estiveram na etapa I, por razões particulares, não puderam permanecer como professores-supervisores.

16 Reprodução da resposta dos estudantes, em Libras, por meio do Sistema de Transcrição de Línguas de Sinais proposto por Felipe e Monteiro (2004).

${ }^{17}$ Assunto abordado mais adiante. 
metodologias e recursos, como também um tipo de pensamento por complexos por estudantes surdos, elencado na perspectiva vygotskyana, os quais têm contato com a LS tardiamente. Desse modo, no sentido de promover um nível prospecto, a atividade proposta na sequência foi a de que trouxessem livros de Português de todos os anos e ambientes de ensino (ETAPA 2 da SF). Em duplas, os discentes deveriam analisar os materiais, os conteúdos (gramaticais, discursivos, gêneros textuais, propostas de atividades escritas, entre outras), os tipos de metodologias utilizadas pelos professores e planos de Libras (das escolas específicas) e de Português das escolas (específicas para surdos e das regulares), no sentido de fazerem inferências da importância do estudo e do ensino de uma língua aos seus próprios nativos e elaborarem hipóteses, proposições e diferentes materiais didáticos na perspectiva visual dos aprendizes surdos.

No primeiro momento, no entanto, alguns discentes ouvintes questionaram: "Por que pensar a partir do Português se estamos tratando deensino de Libras?". Os discentes surdos disseram: "LIBRASPORTUGUÊS NADA-A-VER"18. Desse modo, aproveitando o estranhamento dos estudantes, os professores-supervisores direcionaram o olhar da turma ao conceito de língua materna/primeira língua, e toda a sua riqueza a ser ministrada aos seus nativos.

Estamos longe de pretender uma prática reducionista ao refletir, na troca entre pares e estes com toda a turma, uma proposta que comparasse o ensino de Libras como L1 ao de Português como L1. Ao contrário, como a semente de uma perspectiva rizomática (DELEUZE; GUATTARI, 1925/1995), da qual foram extraídas diferentes ramificações e criativas propostas de aulas e atividades, efetivou-se a ETAPA 3 da SF. Nesta, os estudantes fizeram suas inferências, estabeleceram discussões entre si quanto aos programas, elaboraram suas hipóteses e analisaram possíveis equívocos e direcionamentos do que seria um currículo de Libras para surdos, descolando da ideia do ensino de Libras para ouvintes ou do português para surdos (ambos os ensinos como L2).

Considerando, então, as respostas iniciais que apontavam o ambiente com amplo e desafiante percurso a construir, já que não demonstraram uma ideia concreta do ensino de Libras como língua materna, nesta fase (ETAPA 3 da SF), observou-se, nas expressões e movimentos dos discentes, um salto consideravelmente qualitativo.

${ }^{18}$ Fala de estudante surda, conforme o Sistema de Transcrição de Línguas de Sinais proposto por Felipe e Monteiro (2004). 
V. 8 (3)

$447-468$ out-dez 2018

Vale ressaltar que o acompanhamento de perto e a mediação de professores através de reflexões e não de respostas prontas são fundamentais, em especial nos momentos de ebulição de questionamentos, hipóteses e elaborações, pois corroboram o que diz Sousa (2017, p. 57):

ele [o professor] deve movimentar-se na sala e observar o que eles [os discentes] estão fazendo, não apenas para saber quais suas dificuldades, mas para fazer a mediação necessária, no sentido de ajudá-los na superação de seus limites, sem dar respostas. Assim, é importante que ele faça uso de perguntas, diante de situações verificadas na resolução do problema.

Assim, lançados os questionamentos e sendo encaminhadas as etapas sucessivas, obtiveram-se diversos planos e uma riqueza de materiais numa Pedagogia Visual. As experiências foram registradas em vídeo, nos relatórios em Libras, dos quais se extraiu o seguinte excerto do depoimento de uma estudante-estagiária:

\section{Depoimento 1}

A adaptação de português como L1 para a Libras, na minha opinião, foi uma proposta bem inovadora e de reflexão... Você saber que a Libras pode ser dividida em conteúdos, que ela tem uma gramática, que se pode trabalhar com classificadores, ela tem como trabalhar textos, tudo o que se trabalha da língua portuguesa como L1, dá pra se trabalhar em Libras como L1 também. (...) A gente compara muito e até se perde com o ensino de Libras como L2 no ensino de L1 (...) É importante trabalhar cada conteúdo a seu tempo... a escrita de sinais, a literatura, gêneros textuais diversos... os classificadores, gramática... tantos conteúdos e todos eles precisam ser trabalhados com os aprendizes surdos... (...) para que eles se apropriem da própria língua. (Marlene $)^{19}$

Nessa perspectiva, após as reflexões e discussão sobre conhecimentos prévios que cada grupo de estudantes - surdos e ouvintes - tinha acerca da primeira língua e suas experiências no ensino de Libras, e a elaboração de propostas e materiais visuais, passou-se à próxima fase, a ETAPA 4 da SF, na qual, com a aplicação do que foi construído nas fases anteriores, os discentes puderam (com)provar um modelo geral, um conhecimento novo, que consistiu na construção de propostas de planos anuais (de Curso) com diferentes planos de aulas de acordo com os

${ }_{19}$ Por razões éticas, os depoimentos foram liberados pelos estudantes-estagiários, que assinaram o Termo de Consentimento Livre e Esclarecido. Além disso, suas identidades seguem preservadas por nomes fictícios. 
conteúdos elencados. Nos planos de aula, a Libras foi abordada em suas diferentes nuances: aspectos culturais, literatura, gramática, escrita em signwriting, tudo em contexto interativo. Essa última fase (referente à prova, Etapa 4 da SF) foi desenvolvida, no semestre 2017.2, no período destinado à regência, no qual as duplas trocavam ideias entre si e com outras duplas, ministravam suas aulas, testavam seus procedimentos, a fim de obterem resultados cada vez mais qualitativos em aulas posteriores até o final do ECS, quando chegou o período de elaboração de seus relatórios.

Nesse momento de sistematização, um estudante ouvinte (não-surdo), que atuou em parceria com uma colega surda, avaliou sua experiência, retratada no excerto do próximo depoimento:

Depoimento 2:

No segundo (Libras como L1 - II) tivemos a mudança dos orientadores. Nesse estágio (etapa) tínhamos como foco o planejamento e a confecção de um material didático bilíngue.

[...]De início tivemos uma atividade totalmente diferente, comparar um Livro de Português do ensino médio e seus conteúdos programáticos e adaptar para a disciplina de Libras. Lembro que pesquisei na internet livros e materiais da disciplina de Libras e quase não encontrei, até mesmo os próprios surdos que estudaram em escolas de surdos não tinham noção dos conteúdos para cada série. Assim, passamos a refletir sobre isso com outros olhos, buscando soluções para mudar essa realidade; afinal, a Libras é uma língua tão rica quanto o português. Por que, então, os conteúdos para o ensino de Libras como língua materna se assemelham aos conteúdos de cursos básicos para ouvintes (Libras como L2)?

[...] Outra atividade multidisciplinar no estágio foi a confecção de um material visual que refletia sobre a realidade de uma escola bilíngue, mostrando, de fato, o que seria essa escola, nos fazendo entender que ainda estamos distantes desse sonho, mas que temos sabedoria e visão crítica suficiente para ajudar a construí-lo. (Pedro)

Esse depoimento sintetiza, ao lado de outros depoimentos dos estudantes-estagiários, a importância do estágio e a assertividade do trabalho desenvolvido no ECS, com as diferentes fases metodológicas, mas também evidencia as lacunas existentes nos espaços de ensino de Libras, em especial no que se refere à inexistência de um currículo sistematizado. Sobre esse aspecto, Basso, Strobel e Masutti (2009, p. 20) destacam: 
V. 8 (3)

447-468 out-dez 2018

A falta de um currículo sistematizado de Libras como primeira língua para alunos surdos na Educação Básica pode trazer como consequência a opção por alternativas com base no ensino de segunda língua [...] Muitas vezes o ensino de Libras acontece na forma de cursos isolados ou desvinculados das instituições educativas e os programas destes cursos se resumem à descrição de conteúdos e metodologias (aulas expositivas dialogadas, teatro, piadas e histórias em sinais).

Esse ressentimento, revelado tanto por estagiários ouvintes quanto pelos surdos (bem como pelos professores surdos nas escolas), é comum em diferentes partes do País. Há que se investir em pesquisas nesse sentido. A primeira turma de Letras Libras, que se desenvolveu em caráter semipresencial, no período de 2006-2010, já constatou esse vácuo, e, pelo que se viu nas experiências do ECS em foco, ainda permanecem os desencontros conceituais e as lacunas no ponto de vista curricular.

Desse modo, com os passos e concepções apresentados, passamos à próxima seção, que se refere à síntese das análises e resultados.

\section{Análise do processo do ECS em foco e resultados preliminares}

No contexto do ensino de Libras, lamentavelmente, há uma prevalência de aulas dicionarizadas, seja em aulas ministradas para discentes surdos (Libras como L1), seja em aulas ministradas para discentes ouvintes (Libras como L2). Dessa realidade, fica o desapontamento dos estudantes registrado em seus relatórios de final de Estágio. Nestes, retratou-se o quão necessária é a definição e a sistematização do currículo de Libras como L1.

O olhar para a Libras como L1 foi comparado ao olhar voltado ao Português como L1, a fim de ser tomado apenas como base às experiências dos próprios discentes-estagiários, surdos e ouvintes, que somente destacavam o ensino de Libras para ouvintes, assim como diziam "PORTUGUÊS PRÓPRIO OUVINTES, L2 [PARA] SURDOS. LIBRAS L2 [PARA] OUVINTES, L1 [PARA] SURDOS". A expectativa era a de que os ouvintes, que estudaram o Português como L1, percebessem como culturalmente lhes foi ministrado o ensino de Português na escola e trocassem ideias com seus colegas surdos, já que a experiência que tinham, nos seus registros do período de Observação do ECS ( $7^{\circ}$ semestre), era a do ensino de Libras como L2; isso era o que tinham latente na 
memória. Esperava-se, ainda, que os estagiários surdos pudessem avaliar e, conscientes, se "recusarem" a aplicar uma abordagem de Libras como L2 para seus pares surdos. O resultado foi animador, pois a visão dos surdos e dos ouvintes permitiu que, na troca de experiências, eles observassem que o caminho estava a ser construído e que podiam ser partícipes.

Desse modo, movidos pelos princípios sociointeracionistas, pela consciência metalinguística, e por meio da metodologia já aludida, dividida em sessões didáticas, os estagiários (surdos) concluíram que precisariam favorecer a aquisição formal da sua própria língua aos seus pares, isto é, constataram a obviedade de que os surdos devem aprender Libras como L1, salvaguardada a modalidade e especificidade da língua, da mesma forma que ouvintes aprendem português como materna.

Ao rememorar todo esse processo, passados sete anos da conclusão da primeira turma de Letras Libras, ofertada pela UFSC, e com uma caminhada já realizada pelos egressos, hoje professores atuantes em diversos espaços escolares e/ou acadêmicos, não é possível conceber distorções no âmbito do ensino de Libras, visto que as abordagens de ensino para primeira e segunda línguas são distintas e isso tem implicações diretamente relacionadas a espaço físico, enturmação, currículo e práticas metodológicas, o que corrobora a importância da sistematização de um currículo de Libras como L1, como destacam Basso, Strobel e Masutti (2009, p. 20) ao salientar que:

este currículo somente terá sentido real e valor como instrumento de empoderamento a partir das práticas pedagógicas vinculadas a uma postura política do professor como membro da comunidade surda e representante de sua cultura.

Nesse contexto, ressaltem-se os aspectos identitários e culturais, presentes na afirmação de um currículo, os quais ficam evidentes no depoimento de uma estudante-estagiária surda: 
V. 8 (3)

$447-468$ out-dez 2018

Depoimento 3

Atuar na regência de ensino de Libras como L1, para mim, foi um grande desafio, pois eu já tinha experiência de ensino de Libras como L2 numa escola para ouvintes, mas ensinar para estudantes surdos foi a primeira vez. Dar aulas para aprendizes surdos me deu também muito prazer, porque eles são meus iguais, meus pares! Gostei muito de organizar as aulas, as estratégias de ensino, preparar atividades, material visual, as imagens, organizar os power points, utilizar todos os recursos disponíveis, como o quadro branco, escrevendo, colocando cartazes, de modo que os estudantes discutissem entre si sobre o que era mostrado a respeito da temática. A professora da sala deu a mim e ao Pedro, meu parceiro, dois temas diferentes. Para ele, Educação Inclusiva, e para mim, Educação Bilíngue, e nós trabalhamos contextualizando e comparando as duas temáticas, explorando desenhos... Para mim, foi uma experiência muito boa! Também a professora de Estágio orientou como fazer, como ensinar... foi muito boa essa experiência inicial. Adorei!!! Quero continuar lecionando em escola como o ICES. Tomara que consiga ser professora de lá futuramente. Quero agradecer muito pelas explicações! (RAÍSSA)

Nesse contexto, na sistematização da proposta final, o processo do estágio foi validado pelos discentes estagiários. A validação de cada passo metodológico foi feita conforme os estagiários iam tendo contato com os discentes das escolas, com os professores supervisores do campo (escola), e nos encontros presenciais na UFC, pois, de acordo com as orientações do Manual de Estágio da UFC, a construção do conhecimento nas atividades de ECS prima pela docência compartilhada, quando a prática do estudante estagiário é supervisionada pelo professor da instituição de ensino superior que oferece a Licenciatura e pelo professor da sala de aula da escola em que o estágio acontece.

\section{Considerações finais}

Este artigo pretendeu partilhar experiências do estágio supervisionado do Curso de Licenciatura em Letras-Libras, no ensino da Língua de Sinais Brasileira (Libras ou LSB) como primeira língua (L1), discutindo seu processo e dados, sob três aspectos interrelacionados: (a) o estágio como vivência reflexiva e colaborativa; (b) a imersão do estudante em prática docente sociointeracionista, refletindo sobre os 
conceitos de língua materna e o currículo de Libras como L1; e (c) a escola, território de produção de cultura, lugar de (des)territorialização dos estágios e (des)construção de identidades dos estudantes.

Ao rememorar todo o processo do ECS desse grupo específico de discentes do curso de Letras Libras da UFC, entre outras questões, emerge uma reflexão antiga, mas que ainda é necessária, posto não ter-se cumprido ainda: a sistematização de um currículo voltado para o Ensino de Língua de Sinais Brasileira como primeira língua a ser discutido e empregado, também, em práticas de estágio.

A sistematização desse currículo é fundamental e requer a definição de referenciais teórico-metodológicos, alguns dos quais foram elencados nesse estudo, como o ideário sociointeracionista, e a adoção do o princípio do estágio enquanto locus para produção de conhecimento e incorporação de uma postura de investigação, reflexão e intervenção.

Tais referenciais trouxeram importantes contribuições ao ensino da língua de sinais, no contexto de estudo do funcionamento discursivo de um sistema semiótico e simbólico, contextualizado e determinado sócio-historicamente. Diferentemente da abordagem estruturalista, os enfoques norteadores do estudo não prioriza(ra) $\mathrm{m}$ as formas linguísticas em um sistema fechado em si mesmo, mas, sobretudo, no processo de interação verbal, no qual a língua vai assumindo formas e sentidos na relação discursiva.

No que tange às orientações de estágio à luz do Manual da UFC (UFC, 2016a), o estudo mostra que o estágio em questão cumpriu seus objetivos, pois avançou, foi além do desenvolvimento da atividade de docência. Conforme o referido documento, o ECS deve ser visto como atividades de vivência de diferentes práticas ligadas ao contexto escolar, como aquelas relacionadas ao planejamento, à gestão e à avaliação de propostas pedagógicas. Esse objetivo atende ao Art. 13 da LDB n. ${ }^{0}$ 9.394/1996, o qual preconiza que o docente deve envolver-se, além da prática de sala de aula, em atividades de planejamento, como a elaboração da proposta. Vale destacar que essas vertentes encontramse em construção nas (re)definições do Programa de ECS constante no PPC do curso em discussão.

As escolas específicas de/para surdos constituem um rico espaço de produção linguístico cultural dos educandos surdos, mas ainda com arestas referentes à elaboração de material didático visual, à efetivação de uma proposta efetivamente bilíngue, à definição de uma dinâmica didática adequada para o ensino de Português como L2 e, 
v. 8 (3)

447-468 out-dez 2018

em especial, à efetivação de um ensino de Libras como L1, de fato, que vise à função comunitária da língua e consequente proficiência/ domínio por seus aprendizes. Tal prática deve ser alicerçada nas bases de um currículo sistematizado, com abordagens coerentes e estratégias metodológicas compatíveis com o ensino da língua proposta, e concepções interculturais, entre outros aspectos relevantes ao ensino.

Destarte, urge a sistematização do ensino da Libras como L1, seja nas escolas, seja nos Estágios obrigatórios, de modo que os discentes surdos sejam levados à compreensão e ao uso funcional de sua própria língua, pois, no ensino de qualquer língua como materna, espera-se que a escola incremente o repertório verbal dos aprendizes, aumentando as possibilidades de adaptação dos falantes às diferentes situações de comunicação e às funções variadas de utilização da língua falada/sinalizada (GAGNÉ, 2002). Assim sendo, cabe à escola oportunizar aos estudantes todas as chances de apropriação linguística funcional e privilegiada por parte de toda a coletividade. Vale destacar que as reflexões levantadas nesse estudo não buscam criticar professores nem as escolas-campo de estágio, mas constatar a necessidade de se debruçar sobre a referida temática e fazer didático.

Por fim, muitos aspectos, do ponto de vista científico e metodológico, registrados na experiência ora referida, tais como as diferenças linguísticas, diferenças de graus de proficiência entre os discentes, a perspectiva inter e visuocultural, entre outros requerem ser considerados na continuidade desse estudo, cuja temática demanda uma série de desdobramentos os quais os pesquisadores põem-se a desbravar.

\section{Referências}

ARAÚJO-SOUZA. Maria J. Sequência Fedathi: apresentação e caracterização. In: SOUSA, Francisco Edisom E de.; VASCONCELOS, Francisco H. L.; BORGESNETO, Hermínio [org]. Sequência Fedathi: uma proposta para o ensino de matemática e ciências. Fortaleza, CE: EdUFC, 2013.

BASSO, I. M. de S.; STROBEL, K. L.; MASUTTI, M. Metodologia de Ensino de Libras - L1. In: Curso de Licenciatura em Letras Libras: Disciplina de Metodologia de Ensino de Libras como L1 (texto-base). Florianópolis: UFSC, julho/2009.

BRASIL. Lei de Diretrizes e Bases da Educação $\mathbf{n}^{0}$ 9.394, de 20 de dezembro de 1996. Estabelece as diretrizes e bases da educação nacional. Diário Oficial [da] República Federativa do Brasil. Poder Executivo. Brasília, DF, 23 dez 1996.

BRASIL. Lei n⿳0 $\mathbf{1 0 . 0 9 8}$, de 19 de dezembro de 2000. Estabelece normas gerais e critérios para a promoção da acessibilidade das pessoas portadoras de deficiência, e dá outras providências. Diário Oficial [da] República Federativa do Brasil. Poder Executivo. Brasília, DF, 20 dez 2000. 
BRASIL. Lei no 10.436, de 24 de abril de 2002. Dispõe sobre a Libras, e dá outras providências. Diário Oficial [da] República Federativa do Brasil. Poder Executivo. Brasília, DF, 25 abr 2002.

BRASIL. Decreto $\mathbf{n}^{\mathbf{0}} \mathbf{5 . 6 2 6}$, de 22 de dezembro de 2005. Regulamenta a Lei $\mathrm{n}^{\mathrm{O}}$ 10.436/2002, e dispõe sobre a Libras. Diário Oficial [da] República Federativa do Brasil. Poder Executivo. Brasília, DF, 23 dez 2005.

BRASIL. Lei n⿳ $\mathbf{0} \mathbf{1 1 . 7 8 8}$, de 25 de setembro de 2008. Dispõe sobre o estágio de estudantes e dá outras providências. Diário Oficial [da] República Federativa do Brasil. Poder Executivo. Brasília, DF, 26 set 2008.

BORGES-NETO. Hermínio. A Sequência Fedathi no ensino de Matemática. Curitiba, PR: CRV, 2017 a.

BORGES-NETO. Hermínio. A Sequência Fedathi além das ciências duras. Curitiba, PR: CRV, $2017 \mathrm{~b}$.

DELEUZE, Gilles.; GUATTARI, Félix. Mil platôs: capitalismo e esquizofrenia. (Trad.: Aurélio Guerra Neto e Célia Pinto Costa). Rio de Janeiro: Ed. 34, 1995 [1925].

GAGNÉ, Gilles. A Norma e o ensino da língua materna. In: BAGNO, Marcos; STUBBS, Michael; GAGNÉ, Gilles. Língua materna: letramento, variação e ensino. São Paulo: Parábola Editorial, p. 163-237, 2002.

FELIPE, Tanya A.; MONTEIRO, Myrna Salerno. Libras em contexto: curso básico. Livro do Professor. Brasília: Ministério da Educação, 2004.

FRANCO, Maria Amélia S. Pedagogia da Pesquisa-Ação. Educação e pesquisa. São Paulo. V. 31, n.3, p.483-502, set/dez, 2005.

FRIEDRICH, Janette. Lev Vigotski: mediação, aprendizagem e desenvolvimento: uma leitura filosófica e epistemológica. (Trad.: Anna R. Macedo; Eliane G. Lousada). Campinas: Mercado de Letras, 2012.

GIUSTINA, Flávia P. D.; ROSSI, Tânia M. de F. A Consciência metalinguística pragmática e sua relação com a produção escrita. Revista de Linguística Teórica y Aplicada RLA. Concepción (Chile), 46 (2), pp. 29-51 II Sem. 2008.

LABORIT, Emmanuelle. O voo da gaivota. São Paulo: Best Seller, 1994.

LANE, Harlan. A máscara da benevolência: a comunidade surda amordaçada. Tradução de Cristina Reis. Lisboa: Instituto Piaget, 1992.

LEITÃO, Vanda M. Narrativas silenciosas de caminhos cruzados: história social de surdos no Ceará. Tese (Doutorado em Educação Brasileira). Faculdade de Educação, UFC. 2003.

PIMENTEL-SOUZA, Margarida M. P. de. Voando com Gaivotas: um estudo das interações na educação de surdos. Dissertação (Mestrado em Educação Brasileira). Pró-Reitoria de Pesquisa e Pós-Graduação. Fortaleza: UFC, 2008.

SACKS, Oliver. Vendo vozes: uma jornada pelo mundo dos surdos. Tradução Alfredo B.P. de Lemos. Rio de Janeiro: Imago, 1998. 
v. 8 (3)

447-468 out-dez 2018

SOUSA, Francisco Edisom E. A pergunta como estratégia de mediação. In: BORGES-NETO, Hermínio (Org.). Sequência Fedathi no ensino de Matemática. Curitiba-PR, CRV, 2017.

SOARES, Raianny L. A pergunta como estratégia de mediação. In: BORGESNETO, Hermínio (Org.). Sequência Fedathi além das ciências duras. CuritibaPR, CRV, 2017.

STUBBS, Michael. A língua na educação. In: BAGNO, Marcos; STUBBS, Michael; GAGNÉ, Gilles. Língua materna: letramento, variação e ensino. São Paulo: Parábola Editorial, p. 85-162, 2002.

UFC - Universidade Federal do Ceará. Resolução n⿳0 32/CEPE, de 30 de outubro de 2009. Disciplina o Programa de Estágio Curricular Supervisionado para os estudantes dos Cursos Regulares da UFC. [pdf]. Disponível em <wwW.deecc. ufc.br>. Acesso em: 15/02/2017.

UFC. Manual de estágios da UFC. Agência de Estágio - Pró-Reitoria de Extensão. Fortaleza, Imprensa Universitária, 2016a. [pdf]. Disponível em <wWw.estagios.ufc.br/siges/public_html/MANUAL.pdf>. Acesso em: 15 fev. 2017.

UFC. Projeto Pedagógico do Curso de Licenciatura em Letras Libras. Fortaleza, Centro de Humanidades. 2016b. [pdf] Disponível em <wWW.prograd.ufc.br/ letras-libras-fortaleza.pdf> acesso em: 15 fev. 2017.

VYGOTSKY, Lev S. Fundamentos de defectologia. Habana: Pueblo y Educación, 1989.

VYGOTSKY, Lev S. Pensamento e linguagem. Tradução Jefferson L. Camargo. São Paulo: Martins Fontes, 1993. 